\title{
Presencia del cuento modernista en las revistas literarias colombianas de principios del siglo $\mathrm{XX}^{1}$
}

\author{
Danilo Penagos Jaramillo
}

Resumen. Este artículo expone un breve panorama del cuento colombiano y su relación con la estética modernista en seis revistas literarias colombianas de principios de siglo XX. Para ello, se da cuenta, en primera instancia, del lugar que ocupó la aparición de la "Nueva escuela" en estas publicaciones periódicas y luego se describe y analiza el caso específico del cuento en el contexto de su producción.

Palabras clave: cuento colombiano; cuento modernista; "Nueva escuela"; publicaciones periódicas del siglo XX; historia de la literatura colombiana.

\section{[en] Modernist Short Story in the Colombian Literary Magazines from the Beginning of the 20th Century}

\begin{abstract}
This paper shows a brief overview of the Colombian short story and its relation to Modernist aesthetic in six Colombian literary magazines from the beginning of the 20th century. To accomplish this, it first describes the place that the "Nueva escuela" had in these periodicals. Next it describes and analyzes the specific case of the genre in the context in which the short stories were produced.
\end{abstract}

Keywords: Colombian Short Story; Modernist Short Story; “Nueva escuela”; Periodicals from the 20th Century; History of Colombian Literature.

Sumario. 1. Introducción. 2. El modernismo hispanoamericano y las revistas literarias. 3. La aparición de la "Nueva escuela": el modernismo en Colombia. 4. Del cuento modernista en Colombia y sus influencias. 4.1. Autores extranjeros en las revistas literarias colombianas: una gran escala de influencias. 4.2. Autores nacionales: “Todo cambia, todo se transforma”. 5. Consideraciones finales.

Cómo citar: Penagos Jaramillo, D. (2018) Presencia del cuento modernista en las revistas literarias colombianas de principios del siglo XX, en Anales de Literatura Hispanoamericana 47, 37-52.

1 Este artículo se deriva de la investigación "El cuento colombiano en las revistas literarias colombianas (19001950). Estudio histórico y hemerográfico”, se inscribe, además, en el marco de la Estrategia de Sostenibilidad para grupos de investigación CODI 2016-2017 (Universidad de Antioquia) y hace parte de los compromisos asumidos con el estímulo Joven Investigador Universidad de Antioquia 2016-2017

2 Universidad de Antioquia, Medellín. Colombia.

E-mail: danilo.penagos@udea.edu.co 


\section{Propuestas y metas de la ecocrítica: hacia un giro epistemológico}

El modernismo en Colombia ha sido reducido a lo largo de los años, de manera casi que exclusiva, a las figuras de José Asunción Silva, Baldomero Sanín Cano y Guillermo Valencia. Tal vez, a las de Víctor Manuel Londoño o Maximiliano Grillo. Las historias de la literatura colombiana se han encargado de fijar una cantidad muy limitada de nombres relacionados con este movimiento intelectual, cultural y literario; estas son recuentos históricos que no han podido entregar una caracterización amplia del movimiento ni definir de manera clara la acción del modernismo dentro del sistema literario nacional, a excepción de la influencia que tuvo en la poesía. Desde los estudios de Rafael Maya (1961) hasta los de Héctor Orjuela (2010), el modernismo colombiano se ha examinado, simplemente, como la renovación formal y temática de la tradición poética y la apuesta por el uso de un lenguaje propio. Así, este género ha sido entronizado por la crítica y por las historias de la literatura como la máxima expresión del movimiento; tanto, que si en Colombia se abandona, según estos estudios, "el campo de la poesía [y] pasamos al de la novela, poco habría que decir sobre la ascendiente del modernismo" (Henríquez Ureña 1954: 331).

La narrativa modernista en términos generales no ha sido debidamente considerada por los estudiosos dentro del panorama literario nacional. La afirmación de Max Henríquez Ureña de entrada nos hace pensar que esto mismo pasaría con el cuento, más cuando son pocos o casi nulos los estudios que se han encargado de abordar este asunto en Colombia. En Breve historia de la narrativa colombiana. Siglos XVI-XX (2012), Sebastián Pineda Buitrago intenta dar cuenta de los autores y las obras que pudieron estar asociadas a la renovación estética del periodo de entre siglos, no obstante, su preocupación principal en ese trabajo es la novela y no el cuento, a pesar de que se aventure a decir, como lo hiciera René Uribe Ferrer (1979), que Tomás Carrasquilla fue un cultor del cuento modernista en Colombia, afirmación que requiere, más allá de un escaso ejemplo, un amplio análisis. A su vez, los estudios sobre la publicación y edición de libros de cuentos en Colombia a principios del siglo XX han demostrado que la producción de este tipo de materiales ha sido ínfima con respecto a otros momentos editoriales de la cuentística colombiana (Agudelo 2015); en consecuencia, se puede pensar que los estudios críticos e históricos no se han preocupado del cuento modernista colombiano, en tanto que han descuidado, al mismo tiempo, las publicaciones periódicas como fuentes de estudio de la literatura; pese a que estas fueron el principal lugar de producción, edición y divulgación del género a principios del $\mathrm{XX}$.

Con el ánimo de aportar al estudio de la narrativa modernista en Colombia, este artículo expone un breve panorama del cuento y su relación con la estética modernista, mediante el estudio de seis revistas literarias colombianas de principios de siglo XX, cuyos números aparecieron y circularon durante la consolidación del movimiento. Estas, en su orden de publicación, son: La Gruta (Bogotá, 19031904), Germinal (Bogotá, 1904-1905), Revista Nueva. Literatura y Ciencia (Manizales, 1904-1907), Lectura Amena. Revista de Literatura (Medellín, 19041906), Revista Contemporánea, (Bogotá, 1904-1905) y Alpha (1906-1912). El objetivo es dilucidar la incidencia de la estética modernista en el cuento 
colombiano y avanzar en la reflexión sobre la importancia de las publicaciones periódicas en Colombia como espacio de difusión habitual del género y medio propicio para su paulatino crecimiento en el ámbito de las letras colombianas. Para lograrlo se dará cuenta, en primera instancia, de las reflexiones, polémicas y comentarios a propósito del modernismo en estas revistas; en segundo lugar, se describirá y analizará el caso específico del cuento en el contexto de producción de las mismas.

\section{El modernismo hispanoamericano y las revistas literarias}

Durante las dos últimas décadas del siglo XIX se había extendido por Hispanoamérica la polémica sobre el anquilosamiento de las letras y el influjo de la renovación literaria y artística europea, en especial de las vanguardias francesas de fin de siglo. La prosa y la poesía en español tendían a cambios innovadores que daban la espalda a los cánones clasicistas, románticos y costumbristas, para dar cabida a las nuevas tendencias provenientes de París: parnasianismo, decadentismo, simbolismo, realismo y naturalismo. Autores como el cubano José Martí y el mexicano Manuel Gutiérrez Nájera fueron quienes en principio manifestaron un interés particular por cultivar una narrativa acorde con la nueva sensibilidad y su propuesta estética. Nájera fue uno de los primeros en apostarle a una nueva prosa narrativa, de cuño modernista, por medio de la publicación de relatos en la prensa de la época (Pupo Walker 1972). Sin embargo, no es sino hasta la publicación de Azul... (1888) de Rubén Darío que se establecería un punto de inflexión dentro de la literatura hispanoamericana, en especial para el caso de la prosa, en general, y la narrativa, en particular. Las páginas de Azul... reflejan en sus cuentos las transformaciones temáticas y formales originadas en Francia; además de insertar temas y procedimientos narrativos propios, registran una nueva actitud del narrador ante el lenguaje e ingredientes extraños para el momento, por ejemplo, el orientalismo. Para Darío, el cuento era un "género delicado y peligroso, que en los últimos tiempos ha tomado todos los rumbos y todos los vuelos" y estaba siendo animado por "los prestigios de un arte deslumbrador y exquisito, juntando los secretos, las bizarrías artísticas de los maestros antiguos o los virtuosísimos modernos” (1920, p.125-126) ${ }^{3}$. De ahí que la tendencia creativa de los nuevos escritores hispanoamericanos estuviera orientada por la propuesta del arte modernista y por un sentimiento de libertad ante lo tradicional.

Por otra parte, cabe anotar que desde principios de siglo XIX los escritores e intelectuales hispanoamericanos habían encontrado en la prensa un medio propicio para la difusión de ideas políticas, culturales y artísticas, además de exposición de polémicas sobre el deber ser de la literatura nacional en las nacientes repúblicas americanas. No obstante, para finales de siglo, los escritores fueron conscientes de que los medios periódicos debían superar la tendencia ancilar y programática de la literatura. Las revistas literarias se perfilan, pues, como instancia propicia de emergencia y reconocimiento para la difusión de nuevas ideas en torno a lo

Cabe señalar que la mayoría de cuentos publicados en Azul... ya habían ocupado las páginas de periódicos y revistas, como La Época de Santiago de Chile o la Revista de Artes y Letras de la misma ciudad. 
literario. Su carácter especializado serviría para promocionar su credo estético, permitir la libertad artística y un desarrollo escritural más amplio y desligado de situaciones políticas. De este modo, las revistas se convirtieron en órganos de promoción estética, modernización, desarrollo y evolución de las literaturas americanas. En ellas, a diferencia de los periódicos que empezaban a masificar la información y en ese sentido condicionar la producción de contenidos (Ramos 2003), los escritores podían consolidar su autonomía y un proyecto colectivo en relación con su sensibilidad artística; todo sin estar restringidos por el medio en el que publicaban o las demandas de un público lector específico.

En 1894, en Buenos Aires, Darío fundaría junto a Ricardo Jaimes Freyre la Revista de América, órgano por excelencia del movimiento literario continental. Esta se convirtió en un modelo para los agentes literarios que tenían como aspiración cultural e ideológica la renovación estética de la literatura y abrir nuevas brechas en la expresión cultural americana (Carter 1979). Asimismo, venían apareciendo a lo largo del continente otras revistas que compartirían los objetivos presentados en el prospecto de la Revista de América, a saber, la comunión artística, la peregrinación estética, el trabajo por el brillo de la lengua castellana en América y la separación del arte y la literatura de tendencias utilitaristas, esto es, políticas (Revista de América, "Nuestros propósitos”, 1894, nº 1, p. 1).

\section{La aparición de la "Nueva escuela": el modernismo en Colombia}

Colombia no sería ajena a la influencia de este movimiento literario, cultural e intelectual. Las primeras manifestaciones de las nuevas corrientes literarias que ingresaban al país estuvieron en boca del intelectual antiqueño Baldomero Sanín Cano, quien en las páginas de la Revista Gris (Bogotá, 1892-1896), dirigida por Max Grillo y contemporánea de la Revista de América, hizo la primera defensa de la renovación literaria nacional en su artículo titulado "De lo exótico" (Revista Gris, 1894, II (9), pp. 281-292). Años más tarde, en 1904, después de la Guerra de los Mil Días (1899-1902), aparecería en Bogotá una revista que, desde el punto de vista crítico y literario, amplió la perspectiva de la literatura nacional. Bajo la dirección del propio Sanín Cano, la sociedad de la Revista Contemporánea se encargó de difundir y recoger los frutos de la nueva producción literaria colombiana, que se orientaban a la recepción de modelos extranjeros, la experimentación con la lengua y las formas literarias, y la superación de los calamitosos años de la guerra. Max Grillo, defendiendo la labor realizada por el grupo intelectual del cual era parte, decía que la consideración de una "literatura decadente" estaba "acorde a la necesidad que tiene todo arte de renovarse" de ahí que "los procedimientos literarios" de las últimas décadas del siglo XIX hayan experimentado considerables transformaciones afines al espíritu moderno (Revista Contemporánea, 1904, $n^{\circ}$. 2, p. 97) ${ }^{4}$. Julio César Arce, encargado de la revista Germinal, unos meses antes cuando lanzaba su primer número, había anticipado la necesidad de promover en el ambiente letrado "no gérmenes de muerte sino de vida

4 Desde la sociología de la literatura entendemos que el grupo tiene un papel determinante "en la medida en que usa los textos y les concede un valor; asimismo, se encarga, en cada etapa de su circulación, de fijar los usos de la literatura” (Dubois 2014: 21). 
[...] despertar de energías, brotes de esperanza, germinaciones nuevas en el arte, impulsos de juventud frutos de árboles agitados por soplos frescos” (Germinal, "Preliminar", $\mathrm{n}^{\circ}$. 1, p. 2). Queda clara la postura estética de estas publicaciones con respecto al nuevo siglo y a la constitución de una literatura renovada.

La tendencia a producir innovaciones en la forma, el deseo de originalidad, la libertad individual y artística y las ideas del cosmopolitismo llevaron a que se hablara, entonces, de la aparición de una "Nueva escuela" en Colombia. O por lo menos eso podemos leer en las páginas de la Revista Nueva de Manizales, cuando Alfonso Robledo justifica que la llamada "Nueva escuela" había "dado saludable rumbo á la literatura nacional” (Revista Nueva, 1904, nº 11 y 12, pp. 337-343), rompiendo los viejos moldes y sometiendo a nuevos cánones la producción literaria de entre siglos. Estos juicios seguían las polémicas instauradas en 1903 en la revista La Gruta, publicación de la conocida tertulia bogotana La Gruta Simbólica, cuyos miembros debatían constantemente sobre el legado instaurado por la tradición de cuño hispanista y la promoción de las corrientes literarias europeas de origen francés. Allí, Javier Acosta ya había hablado del surgimiento de una "escuela nueva", iniciada por José Asunción Silva, puesto que su obra era una "lucha" que había dado "las primeras voces para hacernos gustar el encanto de las literaturas modernas, [una] lucha que en un principio estuvo circunscrita á un grupo de curiosos" para ese momento era "una batalla en que toman parte todos aquellos á quienes preocupa la manera de expresar bellamente lo humano" (La Gruta, "La escuela nueva y José Asunción Silva”, 1903, nº.17, p. 226).

Así las cosas, Aquilino Villegas también hacía un llamado a los noveles escritores para que tuvieran una reacción natural al "momento social y la fuerza de novedad legítima que en los tiempos modernos espolea los espíritus" (Revista Nueva, 1903, nº 11 y 12, pp. 337-343). Es así que jóvenes escritores como Luis Cano, fundador de Lectura Amena. Revista de literatura, fueron conscientes de la necesidad de cultivar una literatura que respondiera a una nueva realidad sociocultural que exigía la renovación cultural y nuevas formas de estructurar la vida en sociedad, a partir de la modernización de las ideas, así como de la infraestructura y el entorno urbano.

La consolidación de diversos espacios de sociabilidad como las tertulias, las sociedades literarias y la aparición de instituciones como el Centro Artístico de Medellín, especializadas en el desarrollo y la dinamización del ámbito cultural, permitieron que el arte fuera una preocupación de primer orden para la intelectualidad colombiana de principios de siglo. El arte era un medio apropiado para afrontar la crisis finisecular de los valores y sobreponerse a los estragos de la guerra, pues "la decadencia política ó militar de una nación ha sido propicia, según un escritor moderno, á los florecimientos literarios" (Germinal, "Preliminar", 1904, no. 1, p. 2).

En este punto, es importante señalar que los términos decadente, simbolista y modernista fueron utilizados indistintamente por los críticos y escritores de la época, y las discusiones dadas en las revistas apuntaban a defender la tradición anterior o bien, como queda claro en los casos anteriores, a animar la renovación de la literatura colombiana, bajo la influencia de las corrientes literarias francesas y la noción finisecular del "arte por el arte", agrupadas en la figura de una "Nueva escuela". Pero, como era de esperarse, la definición del "deber ser" de una 
literatura es un juego de opuestos, en otras palabras, dialéctico. Los defensores de la tradición estética, emparentados con la tradición filológica hispanista y neoclasicista, romántica o, bien, regionalista, criticaron fuertemente la irrupción de la "Nueva escuela" en Colombia, tanto así que algunos juicios críticos se orientaron a menoscabar el valor de los nuevos escritores y su estilo, diciendo que este no era suficiente en tanto producción literaria para hacer una crítica madura y amplia de las tendencias finiseculares. Para Rafael Espinosa Guzmán (REG), Darío y Silva eran los únicos que se podían incluir dentro de las características de la escuela nueva, y otros autores como Max Grillo, Víctor M. Londoño o Carlos A. Torres eran apenas un asomo de la nueva expresión literaria hispanoamericana ( $\mathrm{La}$ Gruta, "De literatura", 1903, nº. 5, pp. 68-70). Esta pugna intelectual y artística en busca de horizontes estéticos renovadores se consolidó con la aparición de las revistas mencionadas y la propagación del modernismo en los centros culturales y en los distintos espacios de sociabilidad literaria de principios de siglo. A este respecto, otro caso notable y similar a la crítica que hacía REG, son las famosas "Homilías" que Tomás Carrasquilla publicó en la revista Alpha (Medellín, 19061912, 1915). Allí fueron criticados severamente por el antioqueño los jóvenes escritores adheridos a dicha promoción artística y literaria: Luis Cano, Abel Farina y Abel Marín, además de los ya mencionados y reconocidos en el momento, Max Grillo y Víctor M. Londoño, todos ellos agentes de la ruptura. ${ }^{5}$

La caracterización del cuento modernista en Colombia exige inexorablemente delimitar un contexto de producción que, a las claras, es muy amplio, ya que para ese momento ante la polémica instaurada en las revistas alrededor de la "Nueva escuela” y la ausencia de una definición propia del género tanto en nuestra literatura como en la hispanoamericana en general (Pupo-Walker 1972, Bocaz 1987, Mora 1996, Martínez 1999), ni las publicaciones periódicas ni la crítica literaria de la época hicieron una clara distinción sobre los límites del género y tampoco hubo, hasta entrados los años veinte con Horacio Quiroga, una reflexión de los propios autores con respecto a este, o por lo menos no se han encontrado alguna evidencia de ello en el corpus ${ }^{6}$. Ante este horizonte, las revistas literarias determinaron de manera trascendental la poética del cuento, y para el caso de la "Nueva escuela", las fronteras del cuento modernista colindan con los estilos de origen francés, todas respuestas a los cambios traídos por la modernidad, a saber: el dominio de la sociedad burguesa, la crisis del espíritu finisecular y la secularización de las ideas y la cultura (Gutiérrez Girardot 1983).

Con la aparición y la asimilación de las tendencias modernistas, o de la "Nueva escuela", el género cuento se expande en su clasificación y "en materia de nomenclatura empieza a llenarse de un aura cosmopolita", de allí que se pueda aducir, según Bocaz, "una estabilización paulatina del vocablo en una acepción próxima a la actual, aunque pasado 1900, todavía [fuera] visible cierta indecisión en las denominaciones” (1987: 94). En este sentido, se analiza el cuento modernista en Colombia en función de una ideología de grupo o propuesta estética, que por lo

5 Sobre la discusión crítica que se dio en las revistas literarias de principios de siglo XX, con respecto a la ruptura de la "Nueva escuela”, véase el trabajo de G. Bedoya y D. Barrios (2015), donde se habla, según el caso, de estos autores como agentes de la tradición o los agentes de la ruptura.

6 Es posible que una búsqueda detalla en otras revistas hispanoamericanas permita encontrar alguna caracterización del género, o bien, muestras de una reflexión formal y crítica entorno este. 
dicho hasta aquí fue, claramente, reconocida y denominada como "Nueva escuela". Esta desafió los cánones del momento y dentro de la historia literaria colombiana ha estado en un segundo plano.

\section{Del cuento modernista en Colombia y sus influencias}

La prosa modernista en Hispanoamérica implicó una ruptura con las formas de escritura tradicional y puso en crisis todas las estructuras de composición poéticas y narrativas que tenían un lugar privilegiado en las publicaciones periódicas. Para el caso colombiano, el costumbrismo y el romanticismo eran, quizás, para el periodo estudiado, los dos movimientos poéticos y estilísticos más asentadas; a pesar de ello, fueron los autores de un marcado acento realista quienes tomaron una primera ventaja en cuanto a lo narrativo a finales del siglo XIX y principios del XX o, por lo menos, eso es lo que han mostrado las historias de la literatura colombiana. No obstante, la aparición de la "Nueva escuela", cuyos autores tuvieron una palpable preferencia por la prosa modernista, implicó de entrada un cambio en el devenir de la historia literaria colombiana, gracias a la modificación y reestructuración que estos autores propusieron en la elaboración del relato literario. Esta novedad, como se ha de suponer por el carácter heterogéneo de la "Nueva escuela", no es uniforme. No hay un modelo a seguir, de ahí la ausencia de una definición. Hacer una síntesis de los amplios rasgos narrativos y de la composición poética de los cuentos modernistas publicados en las revistas literarias que se han mencionado y analizar sus temáticas a profundidad es una labor que no podemos emprender ahora, pues por su complejidad requiere una elaboración particular. Sin embargo, se dará cuenta de algunas características sobresalientes de un género que rompe sus fronteras, pero que a la vez buscó autonomía dentro del sistema literario colombiano.

Al hacer un balance del número de cuentos publicados en las seis revistas mencionadas anteriormente, se evidencia que existe una apropiación amplia de un género, que a la par de la crítica literaria, empezaba a ganar un espacio dentro de las revistas literarias colombianas, mas no en las publicaciones en formato libro (Agudelo 2015). Las revistas Germinal, Revista Nueva y Lectura Amena, agrupadas alrededor de una apuesta cultural consciente de la necesidad de renovar el panorama literario colombiano bajo un mismo proyecto estético, dedicaron sus páginas a la publicación de cuentos de autores colombianos y extranjeros, asociados en su mayoría a las distintas disposiciones estéticas propuestas por la escuela nueva. La Revista Contemporánea, dedicada principalmente a la crítica, publicó una cantidad escasa de cuentos, pero no dejó de estar afiliada al movimiento literario modernista. La Gruta y Alpha, por el contrario, fueron revistas cuyos principios estéticos estuvieron dados a partir de un carácter más difuso y ecléctico. Las polémicas instauradas dentro de estas revistas alrededor de la "Nueva escuela" y la influencia de los movimientos franceses aparecieron a menudo sin establecerse como protagónicas. Con todo, estas dos revistas también publicaron algunos cuentos modernistas de autores asociados con las poéticas finiseculares decadentes, pues desde sus primeras páginas, por lo menos para el caso de La Gruta, la intención era clara: publicar a los "buenos literatos del país, 
viejos y nuevos, clásicos y simbolistas, y ya esto le da fuerza tál, que de poco valdrán los esfuerzos del Gran Galoto en su contra, si es que tropezamos con él.” (La Gruta, “La Semana”, no. 2, p. 20). Hecho que muestra cómo dentro de la renovación literaria era necesaria la apertura del campo literario colombiano a otras literaturas.

\subsection{Autores extranjeros en las revistas literarias colombianas: una gran escala de influencias}

La presencia e influencia de la literatura francesa finisecular es por obvias razones insoslayable, y aunque la cifra de cuentos publicados que se pueda adjudicar a autores inscritos al decadentismo y el parnasianismo no asciende a más de treinta relatos en las seis revistas, los textos narrativos que aparecieron en estas publicaciones periódicas no fueron menoscabados por el grupo intelectual a cargo de las mismas. La apreciación —no reproducción— de las literaturas extranjeras no era un hecho de segundo grado, sino que corría a la par de la divulgación de una auténtica expresión literaria americana.

En las revistas abundan traducciones tomadas de otras revistas o realizadas por reconocidos escritores, como las que se publicaron de Paul Margueritte traducido por Silva- en Germinal'. Otro caso más notable, quizá, sea el del francés Catulle Mendès; su cuento “El escollo eterno" apareció simultáneamente en las revistas Lectura Amena y en la Revista Nueva ${ }^{8}$. Este autor parnasiano era un referente de primer orden para los autores hispanoamericanos, o por lo menos eso lo demuestran los comentarios de Darío cuando en "Historia de mis libros" señala que "fue Catulle Mendès mi verdadero iniciador, un Mendès traducido, pues mi francés todavía era precario. Algunos de sus cuentos lírico-eróticos, una que otra poesía de las comprendidas en el Parnasse contemporain fueron para mí una revelación” (1916: 10); o el juicio de José Asunción Silva en una carta dirigida a Baldomero Sanín Cano desde Caracas en 1884, donde habla sobre los "Rubéndariacos, imitadores de Catulle Mendès como cuentista" (1995: 101). Otros escritores franceses como Remy de Gourmont, Leconte de Lisle, Joris-Karl Huymans, Jean Richepin, Marcel Shwob o Alphonse Daudet son de relativa importancia y tuvieron mucha influencia en la "Nueva escuela", tanto en poesía como en narrativa ${ }^{9}$. Asimismo, cuentistas franceses reconocidos hoy como maestros del cuento moderno —entendido de un modo general, no como

“Pataguya” (1904, no. 1, pp. 2-4) y “La pulsera” (1904, nº. 2, pp. 25-27).

$8 \quad$ Véanse el número 2 de Lectura amena (1904: 36-37) y el número 9 y 10 de Revista Nueva (1904: 306). También de este autor se pueden encontrar los cuentos: "La criadita” (Lectura Amena, 1904, nº. 24, pp. 505509); “La flor que tiembla” (Germinal, 1905, nº 18, pp. 282-282) y “La maldita castigada” (Revista Nueva, 1906, no. (s.d.), pp. 128-130).

9 De estos autores podemos traer a colación los cuentos "La metamorfosis de Diana”, de De Gourmont publicado en Germinal (1904, $\mathrm{n}^{\circ}$. 6, pp. 93-94) y "Un episodio del juicio final” (Revista Contemporánea, 1905, no. 5, pp. 453-455). "El fin del hombre” de Lisle (Lectura Amena, 1905, no. 19 y 20, pp. 424-425). "El conductor del ómnibus” de Huymans (Lectura Amena, 1905, n. 21, pp. 450-452). De Jean Richepin "Buenos días señor!” (Revista Nueva, 1905, no. 11 y 12, pp. 367-373) y “Estrella extinta” (Alpha, 1911, no. 61-62, pp. 40-43). "La cruzada de los niños” de Marcel Shwob (Revista Contemporánea, 1904, nº. 3, pp. 242-264). "La última clase. Narraciones de un muchacho alsaciano” (Lectura Amena, 1905, no. 14 y 15, pp. 289-293, reeditado en Sábado, 1922, nº. 54, pp. 652-654) y “Un matrimonio de cantantes” (Lectura Amena, 1905, n”. 26 y 27, pp. 581-584) de Daudet. 
modernista—, también circularon en las páginas de estas revistas literarias, Guy de Maupassant, por ejemplo ${ }^{10}$.

La necesidad por parte de los creadores colombianos, comunidad de interpretación que se proclamaba amplia, de asimilar y apropiarse de los modelos extranjeros como referente para el desarrollo la nueva producción cuentística y literaria del país, era síntoma fehaciente de una tendencia estética que se asumía cosmopolita. Por ello, los franceses no eran los únicos que incidían dentro de esta nueva propuesta literaria. En esta medida, tuvieron lugar en las páginas de las publicaciones periódicas colombianas aquellos autores que de uno u otro modo se consagraron como referentes de la literatura decimonónica finisecular como narradores o autores que por sus posturas estéticas eran asociados con la decadencia. León Tolstoi, Máximo Gorki e Iván Turgénev ${ }^{11}$, desde Rusia, serían una muestra de la lectura de autores consagrados; Oscar Wilde ${ }^{12}$ para el caso inglés; Gabrielle D’Anunzzio ${ }^{13}$ por Italia y Albert Mockel ${ }^{14}$ por Bélgica, harían su parte como representantes del espíritu finisecular.

La literatura española también aportaría una variedad amplia de cuentos de escritores adheridos al modernismo español. Ramón del Valle-Inclán, llamado "el José Asunción Silva de España” por Carrasquilla (“Homilía No 2", Alpha, 1906, I, $\mathrm{n}^{\circ} .8$ y 9, pp. 285-314), es quien tuvo mayor presencia en las páginas de las revistas estudiadas ${ }^{15}$. También aparecen allí los nombres de autores de menor reconocimiento en la actualidad como Santiago Rusiñol, Gregorio Martínez Sierra y Alejandro Sawa, todos ellos alejados del casticismo español promovido, entre otros, por Miguel de Unamuno ${ }^{16}$. Otro autor al cual se le hizo espacio en estas revistas fue Jacinto Benavente, el Nobel español, quien fue elogiado por los intelectuales colombianos adheridos a la "Nueva escuela"; Aquilino Villegas, por ejemplo, lo tuvo como un referente cuyo aporte, aunque nimio, fue de vital importancia para la compresión de lo que era el movimiento, como se verá más adelante.

10 De Maupassant se publicaron los cuentos: "El diablo” (Revista Nueva, 1904, nº. 6, pp. 192-199); “Ante el cadáver de un filósofo" (Germinal, 1904, no. 11 y 12, pp. 172-173); "La muerta” (Germinal, 1905, n. 17, pp. 261-263); “El paraguas” (Lectura Amena, 1904, n. 2, pp. 21-26) y "La leyenda del monte San Miguel” (Lectura Amena, 1904, nº. 4, pp. 71-74).

11 De Tolstoi, fueron publicados: “Karma” (Revista Nueva, 1906, nº. (s.d.), pp. 868-876, Traducción del inglés); “Malachka y Akulina” (Lectura Amena, 1905, n. 16, pp. 337-339) de Gorki: “La ruina del murallón” (Revista Nueva, 1906, $\mathrm{n}^{\circ}$. (s.d.), pp. 120-125) y “Coloquio con la vida” (Lectura Amena, 1905, nº 19 y 20, pp. 415416), y de Turgénev se publicó el cuento “Tres esbozos” (Alpha, 1910, n. 50, pp. 67-71).

12 De Wilde encontramos el cuento "La rosa roja” (Alpha, 1910, no. 50, pp. 53-54).

13 Del italiano D’Annunzio: "El héroe” (Lectura Amena, 1905, nº. 5, pp. 329-332, publicado nuevamente en El Gráfico, 1927, no. 815, pp. 576-677) y “Una rosa llevada al cielo” (Alpha, 1911, nº 63, pp. 104-115).

14 De Albert Mockel: “Foliana y Melivana” (Revista Contemporánea, 1905, no. 5, pp. 393-405) e "Historia del príncipe Feragoto” (Revista Contemporánea, 1905, nº 6, pp. 541-546).

15 De este escritor español se publicaron los cuentos "El rey de la máscara (Cuento color de sangre)” (Lectura Amena, $\mathrm{n}^{\circ}$. 23, pp. 486-489); “El miedo” (Lectura Amena, $\mathrm{n}^{\circ}$. 24, pp. 521-524. Este también fue publicado a posteriori en la revistas Sábado [1929, $\mathrm{n}^{\circ}$. 141, pp. 2209-2210 y Letras y Encajes [1928, nº. 27, pp. 2-4 y 8]) y “Mi hermana Antonia” (Alpha, 1909, n. 43. pp. 262-276).

16 De estos tres autores se pueden mencionar los relatos "El alma de las cosas", de Sawa (Germinal, 1904, n. 11 y 12, pp. 180-181); "Blanca y negro” de Rusiñol (en la revista Riseñol, Lectura Amena, n. 18, pp. 392-392) y de Gregorio Martínez Sierra los cuentos en la Revista Contemporánea “La humilde verdad” (1905, II, nº 1, s. p.) y "Paisajes mudables” (1905, II, nº. 3, s. p.). Es interesante subrayar que Rusiñol y Martínez Sierra tendrán una recepción mayor en la revista El Gráfico (Bogotá, 1910-1941). 
De otro lado, la presencia de autores latinoamericanos es más enriquecedora. Se destaca así la colaboración directa de Amado Nervo, quien tenía correspondencia con Luis Cano y replicó algunos artículos de las revistas colombianas en la Revista Moderna de México (México, 1903-1911) ${ }^{17}$. También aparece Rubén Darío con varios de sus cuentos y como figura tutelar, al lado de Silva, de la renovación literaria continental. ${ }^{18}$ Esta idea se pude constatar en las polémicas desatadas en torno a la "Nueva Escuela”. Las "Homilías” de Carrasquilla, la crítica de REG, así como los textos de Javier Acosta y la "Contra-Homilía” de Max Grillo (Alpha, 1906, n. 3, pp.85-89), dan cuenta de ello. De igual forma, los distintos textos sobre Silva resaltan su valor como precursor y figura de la renovación estética. Un caso notable es el homenaje que le hace Lectura Amena en los números 5 y 6, en una especie de monográfico que incluye textos de y sobre él, donde se distingue su valor dentro de la "Nueva escuela"19.

Hay que mencionar, además, la presencia del escritor guatemalteco Enrique Gómez Carrillo ${ }^{20}$ y del peruano Clemente Palma, representante, según Mora (1996), del cuento modernista de carácter decadentista, y cuyo cuento "Los canastos", publicado por Lectura Amena (1905, n. 26 y 27, pp. 545-547), es hoy un referente de la maestría cuentística de carácter modernista, de ahí su aparición en distintas antologías de cuento y prosa de este movimiento ${ }^{21}$. Cerrando el cuadro se pueden mencionar los nombres de otros narradores igualmente divulgados en las revistas revisadas: Baldomero Lillo, chileno; Julián del Casal, cubano; Manuel Ugarte, argentino; y Pedro Emilio Coll y Alejandro Fernández García, venezolanos ${ }^{22}$.

\subsection{Autores nacionales: “Todo cambia, todo se transforma”}

Dentro del reportorio nacional es de vital importancia entender que con el cuento modernista hubo una apuesta por superar las tendencias del costumbrismo y

17 Las colaboraciones narrativas de Nervo fueron exclusivas para Lectura Amena: “Otras vidas” (1905, $\mathrm{n}^{\circ} .11$, pp. 209-216); “Una humillación” (1905, n’. 16, pp. 324-328) y “El miedo á la muerte (Otras vidas)” (1905, 26 y 27, pp. 571-575).

18 De Rubén Darío se publicaron los cuentos “La canción del oro” (Lectura Amena, 1905, n. 18, pp. 383-385), “El Dios bueno” (Lectura Amena, n. 22, pp. 477-480) y el relato "En el mar” (Lectura Amena, n”. 25, pp. 543-544).

19 En este homenaje sobresalen los textos “El paraguas del Padre León” (Lectura Amena, nº 5 y 6, pp. 100-102) y un fragmento de su novela De sobremesa (nº 5 y 6, pp. 94-95), inédita para ese momento. La importancia de estos radica en que han sido considerados un modelo dentro la prosa modernista hispanoamericana.

20 De Gómez Carrillo reconocido mayoritariamente por sus crónicas, se difundieron en algunos de los números publicados en 1905 de Lectura Amena los cuentos: “Un alma rusa” (nº 17, pp. 363-364); "Psicopatía” (nº 19 y 20, pp. 409-413) y “La nostalgia del dolor” (n. 21, pp. 527-530)

21 Otros dos cuentos de Palma se publicaron en Lectura Amena: "Idealismos” (1905, nº. 13, pp. 250-254) y “El Quinto evangelio" (1905, no. 26 y 27, pp. 545-547).

22 De Baldomero Lillo publicaron el cuento "Sub-sole” fechado en Santiago de Chile en 1907 (Revista Nueva, 1907, no. (s.d.), pp. 1224-1229). De Julián del Casal “La última ilusión” (Lectura Amena, n. 19 y 20, pp. 405408). "Las aldeas”, (Germinal, no. 13, pp. 206-208); "La rosa encantada” (Germinal, n”. 18, pp. 281-282) y “Un sueño de Margot” (Lectura Amena, 1905, no. 26 y 27, pp. 549-552) de Manuel Ugarte. Los relatos "Las razones de bucare” (Germinal, 1904, nº 11 y 12) y "El paraíso de Alonso Herrán” de Pedro Emilio Coll; y, finalmente, los cuentos de Alejandro Fernández García, todos publicados en 1905, "La bandera” (n. 14, pp.209-211), “El sol en el jardín” (n. 15, pp. 229-230), “Los náufragos” (nº. 16, pp.242-245), replicado en Lectura Amena (n. 21, pp. 441-445) y “La recompensa” (n,17, pp. 271-271) en Germinal y “Joya Negra” en Revista Nueva (nº. 20 y 21, pp. 662-668). 
romanticismo, que para principios de siglo ya eran movimientos tardíos o, bien, superar las temáticas regionalistas, de corte localista, propias de la llamada "Escuela antioqueña”"23. Este propósito implicó fuertes críticas por parte de Tomás Carrasquilla, pues la asimilación de modelos franceses creaba, según él, una ruptura con "el ambiente burgués y montañoso" de la élite cultural antioqueña, y trabajar en ello era "violentar las leyes inmutables de la vida" ("Homilía $\mathrm{N}^{\circ}$ 1", Alpha, 1906, $\mathrm{n}^{\circ} .1$, p. 15). Las opiniones esbozadas en sus dos "Homilías" se pueden emparentar con las grandes críticas y detracciones hechas a las propuestas estético-literarias de la "Nueva escuela", desde Max Nordau cuando atacó el decadentismo francés, pasando por la crítica de Juan Valera a Darío, hasta llegar a los comentarios de Luis María Mora para el caso local ${ }^{24}$. Los juicios de Carrasquilla se inscribían en la defensa de una literatura regionalista y endógena, que si bien estaba en contra del real academicismo de la Regeneración y de renovar la tradición hegemónica y filológica, se enfrascaba, a su vez, en las montañas que rodean la ciudad, tanto así que, cuando en Bogotá parecía "que hubiera muerto el espíritu de sociabilidad entre las gentes de letras, en Medellín fundan [...] un centro literario-artístico antioqueño", que cultivaría a gusto de muchos o no una "literatura netamente montañera”. En respuesta a estas iniciativas, el cosmopolitismo, condición sine qua non de la "Nueva escuela", trascendía las fronteras de nacionalismo y regionalismo cultural instaurado y promovido por las élites de los dos centros culturales y de poder más importantes de la época en Colombia, a saber: Bogotá y Medellín. En esta medida, con el espacio dado por las revistas literarias asociadas a la "Nueva escuela”, el cuento, junto con la crítica (Jiménez 1992) y la crónica (Garzón 2010), se convertiría entonces en un género más que oportuno para la realización estética e ideológica de los autores asociados a esta.

El carácter formal que el cuento podía adquirir estaba condicionado por el espacio que ocupaba en la publicación periódica. La prensa creó, como se puede constatar con Alain Vaillant (2005), nuevas formas literarias. El cuento moderno surge en el seno de las publicaciones seriadas y una de sus características más connotadas y polémicas, por su constante relativización, la brevedad, se dio principalmente por la necesidad de ajustarse a las demandas de revistas y periódicos. La escritura de cuentos, como lo considera Ángeles Ezama, para finales del XIX, "se ve favorecida por las dimensiones del mismo, que lo hacen asequible a cualquier tipo de publicación” (1992: 26). En esta medida, la reflexión que hacía Rafael Espinosa Guzmán cuando hablaba de los sonetos de Matías Silva H. como una unidad es muy pertinente, ya que allí destacaba que el estado de la literatura y el de la época exigían que toda composición literaria fuera breve y "de una sugestión intensa para expresar claramente los estados del alma” (Germinal, “Cosas mías”, no. 8, p. 121). Él, junto con Max Grillo, tomó esta demanda como propia y escribió varios relatos denominados en estas revistas como "Cuentos

23 La "Escuela antioqueña” es una agrupación generacional y geográfica que las historias y manuales de la literatura colombiana han acuñado para referirse a una tendencia narrativa que, según Eduardo Pachón Padilla, "supo combinarle al costumbrismo la objetividad del realismo para aplicarlo, con exclusividad, a su comarca nativa” (1980: 63), esto es Antioquia. Dentro de la nómina de autores que participaron de esta tendencia de carácter "regionalista", se han destacado los nombres de Gáspar Chaverrra, Francisco de Paula Rendón, Efe Gómez y Carrasquilla.

24 Véase Mora, L. (1902). Decadencia y simbolismo. Revista de la Instrucción Pública de Colombia, 12 (71 y 72), pp. 348-363. 
cortos o breves”, pues ocupaban máximo dos columnas de las páginas de las revistas donde fueron publicados ${ }^{25}$. Estos cuentos breves podían tener un mayor potencial de lectura para el incipiente mercado editorial (Ramos, 2003), en tanto que, frente al poema rimado, la utilización de la prosa no exigía a un público lector no experto y más heterogéneo.

La adherencia a los moldes de la "Nueva escuela”, cuya hibridación genérica era ilimitada, por decirlo de algún modo, dado que las influencias eran múltiples y heterogéneas, conllevó que autores como Aquilino Villegas, importante colaborador de la Revista Nueva, publicara cuentos de la factura de "Divagaciones. Lo que dijeron los libros” (1904, $\mathrm{n}^{\circ} .9$ y 10, pp. 326-332), donde intentaba una propuesta narrativa que desbordaba los límites entre las formas narrativas y las dramatúrgicas. Este relato que tomaba, por momentos o casi en su totalidad, la forma del guion teatral, era por la misma época, una propuesta que Gómez Carrillo desarrolló en el cuento "Psicopatía", publicado en Lectura Amena (1905, n. 19 y 20, pp. 409-413) y que más adelante Leopoldo Lugones, con el cuento "Dos ilustres lunáticos o la divergencia universal”, confirmaría como tendencia en la Revista Moderna de México en 1910. Cabe señalar que este tipo de narrativa, denominada "relato teatral” o “cuento teatral”, según Ángeles Ezama Gil (1992) estuvo de moda en la prensa del periodo finisecular. Entre sus características principales se encontraba un "sistema dialogal" predominante, el uso de algunas acotaciones y la ausencia de un narrador externo al relato. En la Revista Nueva, y siguiendo esta misma propuesta narrativa, también se publicó un texto titulado "Modernismo. Nuevos moldes" de Jacinto Benavente, que pone a discutir a dos personajes sobre las nuevas tendencias estéticas ${ }^{26}$. Lo más especial de esta adaptación, además de la discusión sobre los nuevos moldes literarios y la importancia de destacar la naturalidad y la "expresión honrada" del artista, es la dedicatoria que lo acompañaba, firmada por A. V. H. —que podría ser Aquilino Villegas-: “A Dn. Tomás Carrasquilla, rabioso prócer antimodernista, autor de dos hiperestésicas Homilías y [se] recomienda la lectura de estos párrafos de un maravilloso artista español" (1906, nº s.d. pp. 1122-1126). La dedicatoria hace patente otra vez la tensión dialéctica entre dos posturas estéticas disímiles, el regionalismo de la "Escuela Antioqueña" y el modernismo de la "Nueva escuela", que querían ganar un espacio de privilegio dentro del sistema literario nacional e instaurarse como instituciones literarias por fuera de los cánones hegemónicos neoclasicistas, costumbristas y románticos.

Esta tensión con la tradición fue de vital importancia para el cuento modernista colombiano, y para la "Nueva escuela" en general, pues en la búsqueda de una expresión literaria propia y autónoma, el cuento se vio atravesado por diversas temáticas, pero a su vez transversales a gran parte de los cuentos publicados por autores colombianos. Una de estas era el sentimiento de espontaneidad del artista, así como el de los protagonistas. Desde la publicación del relato "Sinceridad de

25 Estos relatos son: “Cuentos breves. Cosas que mueren” (La Gruta, 1902, n. 1, pp. 4-5) y "Cuentos breves” (Revista Contemporánea, 1905, $\mathrm{n}^{\circ}$. 4, pp. (s.d.)” de Grillo y “Cuentos cortos: Único beso” (n. 11, p. 150), "Cuentos cortos: El leñateo” (n. 12, pp.167-169) "Cuentos cortos: Almas y flores” (no. 13, p. 176), “Cuentos cortos: Celos de mujer” (n. 20, p. 265) de Espinoza Guzmán, publicados en La Gruta en 1903.

26 Otro texto de este consagrado escritor fue: “Los que se van” (Alpha, $\mathrm{n}^{\circ}$. 50, pp. 41-44). 
artista” de Baldomero Sanín Cano en la Revista Gris (1892, I, nº 1, pp. 28-34) ${ }^{27}$, que aquí consideramos como uno de los primeros cuentos modernistas colombianos, hasta la publicación del cuento "Plumazos", de Abel Farina (Lectura Amena, $\mathrm{n}^{\circ} .14$ y 15, pp. 296-297), estas publicaciones destacaron como principio rector para su realización literaria los sentimientos de franqueza y espontaneidad que le dieran una mayor universalidad a su literatura, puesto que "el arte si quiere interesar busca dos fuentes: la sinceridad y la vida” (Germinal, n. 1, 1904), lo que no descartaba una expresión elaborada, un estilo depurado y poético. De igual manera, surgieron escenarios narrativos cuya impronta estaba ligada y determinada por proyectos de modernización, la exploración en el placer, el lujo y los excesos, lo fantástico o las relaciones de infortunio y desamor, donde la mujer es descrita con la retórica del esteticismo finisecular. Luis Cano, Abel Marín, Carlos Castello, Rafael Montoya Pérez y Javier Acosta fueron autores que en sus cuentos trataron temáticas correspondientes a las inquietudes del fin de $\operatorname{siglo}^{28}$.

Por razones de espacio no analizaremos estos cuentos detalladamente, pero basta decir que estos ofrecen una variedad amplia de fórmulas narrativas que, además de la elección de temas "modernos" como el artista ante la sociedad, la escritura literaria, las referencias a los autores modernistas y filósofos alemanes del siglo XIX, la discusión entre lo clásico y lo nuevo o la mirada hacia Europa, dan muestra de la novedad de sus procedimientos narrativos en el diseño estructural del relato, no solo en su brevedad sino también en la apuesta por la solidaridad orgánica entre formas literarias, como los diferentes usos de la prosa y la utilización de formas intimistas como diarios, memorias o cartas.

\section{Consideraciones finales}

Al ser este trabajo un estudio que analiza el cuento modernista en Colombia en relación a su contexto de producción, queda claro que lo expuesto hasta aquí no es más que una introducción al estudio de las particularidades del cuento en Colombia. Pues, además del modernismo y las tendencias decadentes, convivieron

27 Este cuento es la historia de un poeta que, estancada su producción artística y enfrentado a la crítica literaria y a un nuevo público lector, se ve en la necesidad de encontrar para la creación de un nuevo libro una poética acorde con los tiempos y sinsabores modernos. Es así como una mujer, figura tan cara para el romanticismo y el modernismo, representa un desafío intelectual para el protagonista y es quien le ayuda a encontrar una nueva ruta de expresión natural, llena de vigor y sinceridad artística. Así, el protagonista del cuento busca trascender la realidad social e individual dentro del hastío con mundo moderno. El lenguaje, las referencias intertextuales, la crítica de la condición del artista en la época moderna, donde la producción literaria es subvalorada son elementos de quiebre dentro de la narración y estilo, presentados desde la autorreflexibidad literaria propia del modernismo.

28 De Luis Cano se pueden traer a colación los cuentos “Margot” (Lectura Amena, 1905, no. 13, pp. 255-258, reproducido por la revista Sábado, 1922, n. 54, pp. 656-658), “Del arroyo” (Lectura Amena, 1905, n. 24, pp. 511-514) y "Perdido en la viña” (Alpha, 1911, no. 65-66, pp. 185-190). Abel Marín se destaca con "Polonia” (Lectura Amena, 1905, $\mathrm{n}^{\circ}$. 12, pp. 225-227, publicado también en la sección de cuentos nacionales de El Gráfico, 1911, no. 34, p. 304), “¿...” (Alpha, 1906, n. 7, p. 267). De Carlos Castello se puede destacar en La Gruta "Dulce muerte” (1903, no. 9, pp. 125-127), "Las tres cabezas” (1903, no. 17, p. 221), "Mancha feliz" (1904, no. 23, p. 300) y "Tarde gris” en Germinal (n. 11 y12, p. 179); de Rafael Montoya Pérez "Tu quoque” (Lectura Amena, 1905, no. 11, pp. 201-208) y "Rayo de sol” (Alpha, 1906, no. 4, pp. 158-160); de Javier Acosta los relatos “De Eros” (1903, nº. 6, pp. 86-87) y “Una estrella extinguida” (1903, nº 10, pp. 139-143) publicados en La Gruta. 
en las páginas de dichas revistas cuentos de carácter naturalista y realista. Asimismo, la literatura española que se inscribió dentro de alguna de estas dos tendencias y que aparece publicada en las revistas estudiadas merece ser analizada como un modelo de apropiación literario distinto al caso francés.

Al mismo tiempo, estas páginas no serían suficientes para hacer un análisis sobre todos los rasgos composicionales de cada uno de los cuentos con características modernistas publicados en la presa colombiana de principios del siglo XX. Sería una tarea muy ardua, que exigiría un análisis comparado y la constitución de un corpus antológico de cuentos propios de la época, que permita marcar las diferencias y matices que ofrece un determinado estilo u otro. De ahí que consideraremos en principio los cuentos modernistas en función del grado de afiliación de los autores a una corriente estética, ideológica y cultural dentro de las revistas, pues ofrecer un listado detallado de autores y temáticas es encasillar un fenómeno que evidentemente fue heterogéneo. Estas formaciones de jóvenes escritores, en su mayoría, dieron paso a nuevas formas de escribir y de pensar en Hispanoamérica. Con un análisis más detallado de las revistas como una unidad se reconocería la constitución de una geografía cultural, que proporcionaría datos de gran valor para ahondar en el conflicto entre la escuela santafereña y la escuela antioqueña por el control del capital simbólico dentro sistema literario colombiano. Un estudio más amplio desde la teoría de las transferencias culturales serviría como base para entender las dinámicas del sistema literario colombiano dentro de la coyuntura literaria que generó el modernismo a finales del siglo XIX y principios del siglo XX.

Un balance del número de cuentos escritos por autores afines a la "Nueva escuela" muestra que Lectura Amena fue la revista que dio mayor lugar a estos relatos. Cabe agregar que la recepción y producción de cuentos modernistas no se detuvo con la desaparición de estas revistas. La reproducción de algunos cuentos que ya habían sido publicados en las revistas analizadas en revistas editadas posteriormente, entre estas El Gráfico y Cromos, la edición de otros cuentos de los autores referenciados, así como la aparición de nuevos autores — caso Eduardo Castillo, prolífico cuentista colombiano, un tanto olvidado o desconocido-, son hechos que demuestran la consolidación del cuento modernista dentro de la narrativa colombiana. Por último, traer a colación la noción de "Nueva escuela" como marco general para el análisis de las tendencias narrativas modernistas en la primera década del siglo XX en Colombia lleva a pensar en la necesidad de proponer, dentro de la historia de la literatura colombiana, un nuevo momento de la cuentística nacional, aparte de los fijados por los trabajos antológicos y los manuales de la literatura colombiana, entre estos, "La Escuela antioqueña", "La narrativa caldense de los años 40", "El grupo de Barranquilla”, o "El cuento de la violencia" 29 .

29 Para ver más a este respecto, véase el trabajo de Ana María Agudelo Ochoa, titulado hacia "Hacia una historia del cuento colombiano" (2015). 


\section{Referencias bibliográficas}

\section{Fuentes primarias}

Alpha, Medellín, 1906-1912.

Germinal, Bogotá, 1904-1905.

La Gruta, Bogotá, 1903-1904.

Lectura Amena. Revista de Literatura, Medellín, 1904-1906.

Revista Contemporánea, Bogotá, 1904-1905.

Revista Nueva. Literatura y ciencia, Manizales, 1904-1907.

\section{Obras citadas}

Agudelo Ochoa, Ana, "Hacia una historia del cuento colombiano", Inti: Revista de literatura hispánica, 81 y 82 (2015), pp. 147-169.

Bedoya, Gustavo y Barrios, Diana, "Entre la norma y la ruptura, entre lo clásico y lo moderno. La crítica literaria colombiana en la prensa de 1900 a 1920”, en O. Vallejo (ed.). "La búsqueda de la verdad más que la verdad misma”. Discusiones literarias en las publicaciones periódicas colombianas 1835-1950. Lima-Medellín: Centro de Estudios Literarios Antonio Cornejo Polar-Universidad de Antioquia, 2015, pp. 121157.

Bocaz, Luis, "El cuento latinoamericano como producción cultural: subordinación y autonomía del género”, América: Cahiers du CRICCAL, 2 (1987), pp. 87-111. Disponible en: http://www.persee.fr/doc/ameri_0982-9237_1987_num_2_1_905

Carter, Boyd, “El modernismo en las revistas literarias: 1894”, Chasqui, 8 (2) (1979), pp.518.

Darío, Rubén. Los raros. Madrid: Editorial Mundo Latino, 1920.

—Historia de mis libros, en Antología. Madrid: Librería de la viuda de G. Pueyo, 1916, pp. 9-44.

Dubois, Jacques. La institución de la literatura. Trad. de J. Zapata. Medellín: Editorial Universidad de Antioquia, 2014.

Ezama Gil, Ángeles. El cuento en la prensa y otros cuentos: (aproximación al estudio del relato breve entre 1890 y 1900). Zaragoza: Prensa Universitarias, 1992.

Garzón Agudelo, Leandro, "La crónica: aportes de un género a los estudios históricos sobre la literatura colombiana”, en A. Laverde y O. Vallejo (eds.). Tradiciones y configuraciones discursivas: historia crítica de la literatura colombiana. Elementos para la discusión. Cuadernos de trabajo II. Medellín: La Carreta Editores, 2010, pp. 105-218.

Gutiérrez Girardot, Rafael. El Modernismo. Presupuestos históricos y culturales. Bogotá: Fondo de Cultura Económica y Universidad Externado de Colombia, 1983.

Henríquez Ureña, Max. Breve historia del modernismo. México: Fondo de Cultura Económica, 1978.

Jiménez, David. Historia de la crítica literaria en Colombia. Siglos XIX y XX. Bogotá: Universidad Nacional de Colombia-Instituto Colombiano de Cultura, 1992.

Martínez, Juana, “El cuento hispanoamericano en el siglo XX: Indefiniciones”, Anales de Literatura Hispanoamericana, 28 (1) (1999), pp. 267-282.

Maya, Rafael. Los orígenes del modernismo en Colombia. Bogotá: Biblioteca de Autores Contemporáneos, 1961.

Mora, Gabriela. El cuento modernista hispanoamericano: Manuel Gutiérrez Nájera, Rubén Darío, Leopoldo Lugones, Manuel Díaz Rodríguez, Clemente Palma. Lima-Berkeley: Latinoamericana Editores, 1996. 
Mora, Luis María, “Decadencia y simbolismo”, Revista de la Instrucción Pública de Colombia, 12 (71 y 72) (1902), pp. 348-363.

Orjuela, Héctor. El Modernismo en Colombia: proceso, rasgos y contradiscurso. Bogotá: Guadalupe, 2010.

Pachón Padilla, Eduardo. Cuento colombiano: antología, estudio histórico y analítico. Bogotá: Plaza \& Janes, 1980.

Pineda Buitrago, Sebastián. Breve historia de la narrativa colombiana. Siglos XVI-XX. Bogotá: Siglo de Hombre Editores, 2012.

Pupo-Walker, Enrique, "Notas sobre los rasgos formales del cuento modernista”, Anales de literatura hispanoamericana, I (1972), pp. 469-480. Disponible en: http://revistas.ucm.es/index.php/ALHI/article/view/ALHI7272110469A

Ramos, Julio. Desencuentros de la modernidad en América Latina. Literatura y política en el siglo XIX. Chile: Editorial Cuarto Propio, 2003.

Revista Gris. Bogotá, 1902-1906.

Silva, José Asunción. Cuarenta y cinco cartas, 1881-1896. Bogotá: Arango Editores, 1995.

Uribe Ferrer, René. Antioquia en la literatura y en el folclor. Medellín: Editorial Colina, 1979.

Vaillant, Alain, "Poética de la escritura periódica: cuestiones de método y de historia literaria”, Secuencia. Revista de Historia y Ciencias Sociales, 62 (2005), pp. 195-206. Disponible en: http://www.redalyc.org/articulo.oa?id=319136829009 